\title{
Leukemia-Associated Rho Guanine Nucleotide Exchange Factor and Ras Homolog Family Member C Play a Role in Glioblastoma Cell Invasion and Resistance
}

Zonghui Ding, ${ }^{*}$ Zhiwan Dong, ${ }^{\dagger}$ Yuping Yang, ${ }^{\dagger}$ Shannon P. Fortin Ensign, ${ }^{\ddagger}$ Hemragul Sabit, ${ }^{\S}$ Mitsutoshi Nakada, Rosamaria Ruggieri, ${ }^{\dagger}$ Jean M. Kloss, ${ }^{*}$ Marc Symons, ${ }^{\dagger}$ Nhan L. Tran, ${ }^{*}{ }^{\mathbb{\top}}$ and Joseph C. Loftus ${ }^{*}$

From the Departments of Cancer Biology, ${ }^{*}$ Hematology and Oncology ${ }^{\ddagger}$ and Neurosurgery, ${ }^{\circledR}$ Mayo Clinic Arizona, Scottsdale, Arizona; the Karches Center for Oncology Research, ${ }^{\dagger}$ Feinstein Institute for Medical Research at Northwell Health, Manhasset, New York; and the Department of Neurosurgery, ${ }^{\S}$ Graduate School of Medical Science, Kanazawa University, Kanazawa, Japan

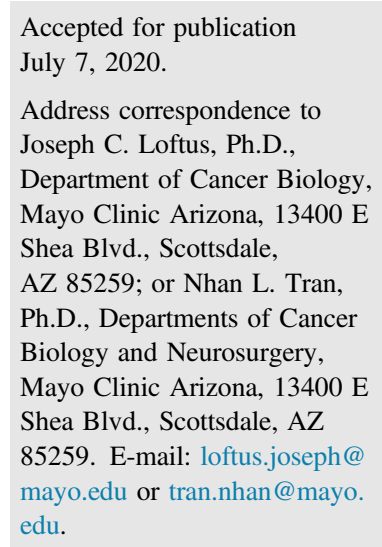

\begin{abstract}
Glioblastoma (GBM) is the most common primary malignant brain cancer in adults. A hallmark of GBM is aggressive invasion of tumor cells into the surrounding normal brain. Both the current standard of care and targeted therapies have largely failed to specifically address this issue. Therefore, identifying key regulators of GBM cell migration and invasion is important. The leukemia-associated Rho guanine nucleotide exchange factor (LARG) has previously been implicated in cell invasion in other tumor types; however, its role in GBM pathobiology remains undefined. Herein, we report that the expression levels of LARG and ras homolog family members $C(R h o C)$, and $A(R h o A)$ increase with glial tumor grade and are highest in GBM. LARG and RhoC protein expression is more prominent in invading cells, whereas RhoA expression is largely restricted to cells in the tumor core. Knockdown of LARG by siRNA inhibits GBM cell migration in vitro and invasion ex vivo in organotypic brain slices. Moreover, siRNA-mediated silencing of RhoC suppresses GBM cell migration in vitro and invasion ex vivo, whereas depletion of RhoA enhances GBM cell migration and invasion, supporting a role for LARG and RhoC in GBM cell migration and invasion. Depletion of LARG increases the sensitivity of GBM cells to temozolomide treatment. Collectively, these results suggest that LARG and RhoC may represent unappreciated targets to inhibit glioma invasion. (Am J Pathol 2020, 190: 2165-2176; https://doi.org/10.1016/j.ajpath.2020.07.005)
\end{abstract}

Glioblastoma (GBM) is an extremely aggressive cancer with a 5-year overall survival rate of $6.8 \%$ after diagnosis. ${ }^{1-4} \mathrm{~A}$ critical issue for effective treatment of these brain cancers is the extensive invasion of individual tumor cells into the adjacent normal brain. These invading cells are largely resistant to chemotherapy and radiation, which virtually assures tumor recurrence. Unfortunately, our understanding of the underlying molecular mechanisms leading to the aggressive behavior of these tumors remains limited. Therefore, there is a critical need for new insights into the underlying molecular mechanisms mediating GBM cell migration and invasion to inform the development of new therapeutic interventions.
Recent studies indicate that the invasiveness of solid tumors involves signaling events downstream of Rho GTPases. ${ }^{5}$ RhoA (also known as RHOA) and RhoC (also known as RHOC), like other members of the small Rho GTPases, regulate essential cellular processes, including cell shape, cell adhesion, and cell migration, via their effects on the

\footnotetext{
Supported by NIH grants R01 NS092955 (J.C.L. and N.L.T.), R01 NS086853 (J.C.L. and N.L.T.), and U01 CA220378-01 (J.C.L. and N.L.T.).

Disclosures: None declared.

Current address of Z.D., Incyte Inc., Augustine Cut-Off, Wilmington, DE; of Y.Y., Sylvester Comprehensive Cancer Center, University of Miami Miller School of Medicine, Miami, FL.
} 
microfilaments and microtubules. ${ }^{6}$ They function as molecular switches that are inactive in the GDP-bound form and active in the GTP-bound form. Their activation is positively regulated by guanine nucleotide exchange factors (GEFs) that catalyze the exchange of bound GDP for GTP. Despite sharing $85 \%$ amino acid sequence identity and activating a number of the same effectors, RhoA and RhoC have been shown to play different roles in cell migration and invasion. ${ }^{7,8}$ There is emerging evidence showing that RhoA inhibits cell invasion, whereas RhoC stimulates it in vitro. ${ }^{9-11}$ RhoC has received additional attention because elevated $\mathrm{RhoC}$ expression has been correlated with increased invasion in a number of cancers, including invasive breast carcinoma, esophageal squamous cell carcinoma, gastric cancer, head and neck cancer, melanoma, non-small-cell lung carcinoma, and ovarian carcinoma. ${ }^{12-20}$ RhoC has been identified as a poor prognostic marker for colon carcinoma, pancreatic adenocarcinoma, and hepatocellular carcinoma. ${ }^{10,21,22}$ Notably, RhoC has been shown to be essential for cancer metastasis in mouse models. ${ }^{16,23}$ Furthermore, RhoC expression is positively correlated with advanced clinical stage and lymph node metastases for patients with squamous cell carcinomas of the head and neck. ${ }^{24}$ Thus, RhoC is a specific predictive marker of lymph node metastasis for patients with squamous cell carcinomas of the head and neck. ${ }^{24}$

The leukemia-associated Rho GEF (LARG, also known as ARHGEF12) was originally identified as a novel fusion partner of the mixed-lineage leukemia protein in an acute myeloid leukemia patient. ${ }^{25}$ LARG is a member of the regulation of G-protein signaling domain containing-GEF family of GEFs that also includes p115RhoGEF and rho guanine nucleotide exchange factor 11 (PDZ-RhoGEF). ${ }^{26}$ Previously, LARG has been shown to activate RhoA, but not Rac1 or Cdc42. ${ }^{27,28}$ LARG has been shown to function downstream of $\mathrm{G}$ protein-coupled receptors, including the thrombin, bombesin, and lysophosphatidic acid receptors, and is activated during cell spreading on fibronectin. ${ }^{29-32}$ LARG also has been implicated in tumor cell invasion. ${ }^{31}$ Copy number variation analysis of the combined Japan and The Cancer Genome Atlas cohorts revealed that LARG was among the genes with significant copy number gains in grade II and III gliomas, implying that LARG might play a role in GBM. ${ }^{33}$ Previously, it was demonstrated that the closely related PDZ-RhoGEF is part of a signalsome in GBM cells containing TROY and Pyk2 and plays a role in the regulation of cell migration and invasion. ${ }^{34}$ However, the role of LARG in GBM pathobiology has not been well defined.

In this study, we investigated the role of LARG as well as its downstream effectors RhoA and RhoC in GBM cell migration and invasion. We identified LARG and $\mathrm{RhoC}$ as important elements in the signaling cascade that regulates GBM cell migration and invasion. These data suggest that LARG and RhoC may represent potential points of vulnerability to limit aggressive GBM cell invasion.

\section{Materials and Methods}

\section{Antibody and Reagents}

The polyclonal anti-LARG antibody (number 22441-1-AP) was purchased from ProteinTech (Rosemont, IL). The rabbit anti-PDZ-RhoGEF polyclonal antibody (number NBP1-06553) was purchased from Novus Biologicals (Littleton, CO). Rabbit anti-RhoC antibody (number 3430), mouse anti-phosphorylated S19 myosin light chain (MLC) 2 antibody (number 3675), rabbit anti-MLC2 (number 3672), rabbit anti-hemagglutinin antibody (number 3724), and mouse antitubulin antibody (number 3873) were obtained from Cell Signaling Technology (Beverly, MA). The mouse anti-RhoA antibody (number sc-418) was obtained from Santa Cruz Biotechnology (Dallas, TX).

\section{Cell Culture}

The U87 GBM cells and human embryonic kidney cell line HEK293 cells (ATCC, Manassas, VA) were grown as adherent monolayers and were cultured in Dulbecco's modified Eagle's medium (Invitrogen, Carlsbad, CA) supplemented with $10 \%$ of fetal bovine serum (Invitrogen), 2 $\mathrm{mmol} / \mathrm{L}$ glutamine, $1 \%$ nonessential amino acids, $100 \mu \mathrm{g} / \mathrm{mL}$ streptomycin, and 100 units $/ \mathrm{mL}$ penicillin. Cells were maintained at $37^{\circ} \mathrm{C}$ with $5 \% \mathrm{CO}_{2}$. GBM10 and GBM43 are primary GBM patient-derived xenografts (PDXs) obtained from the Mayo Clinic Brain SPORE. ${ }^{35}$ Details are available from Mayo Clinic (https://www.mayo.edu/research/labs/ translational-neuro-oncology/mayo-clinic-brain-tumor-patientderived-xenograft-national-resourceloverview, last accessed June 19, 2020). Fresh flank GBM10 and GBM43 tumors were harvested, mechanically disaggregated, and cultured in neurosphere media (Dulbecco's modified Eagle's medium/ F12 supplemented with $2 \% \mathrm{~B}-27,20 \mathrm{ng} / \mathrm{mL}$ epidermal growth factor, and $20 \mathrm{ng} / \mathrm{mL}$ basic fibroblast growth factor).

\section{Immunohistochemistry}

An independent cohort of surgical specimens was obtained (10 low-grade astrocytomas, 10 anaplastic astrocytomas, and 30 GBMs) from the Department of Neurosurgery, Graduate School of Medical Science, Kanazawa University (Kanazawa, Japan) for immunohistochemical validation of LARG, RhoA, and RhoC expression. Tumor samples were harvested following surgical resection and fixed in $4 \%$ paraformaldehyde. All tissues were classified according to World Health Organization classification. ${ }^{36}$ This study was performed in compliance with the guidelines of the Internal Review Board of Kanazawa University and was approved by the Kanazawa University medical ethics committee (number 209). Immunohistochemistry (IHC) was performed on tissue sections (4 $\mu \mathrm{m}$ thick), as previously described. ${ }^{37} \mathrm{~A}$ standard histologic scoring system was used to grade 
A
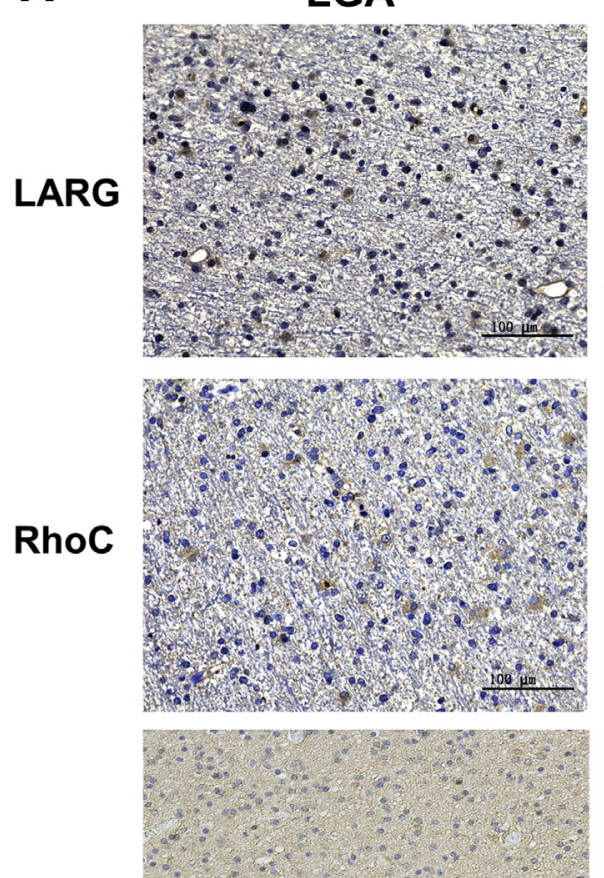

RhoA

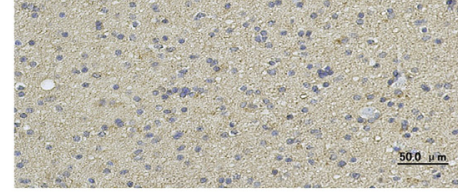

AA
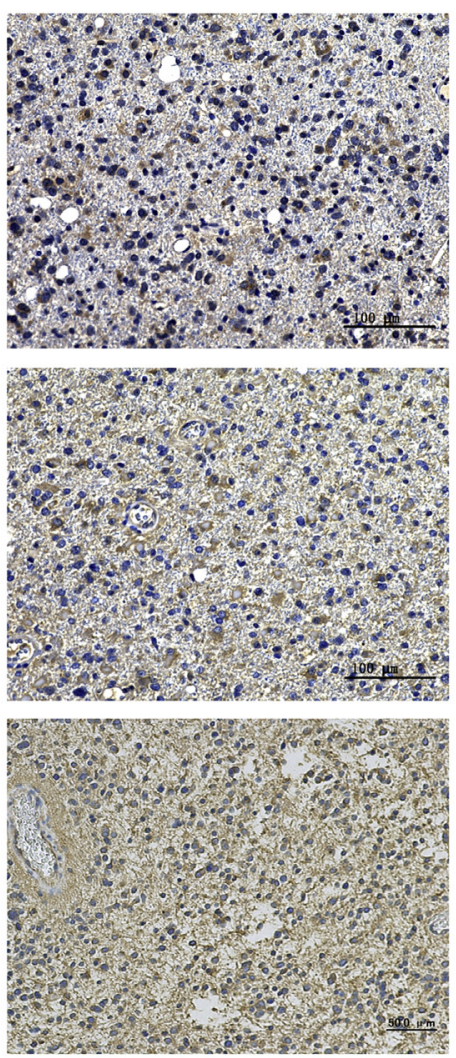

GBM
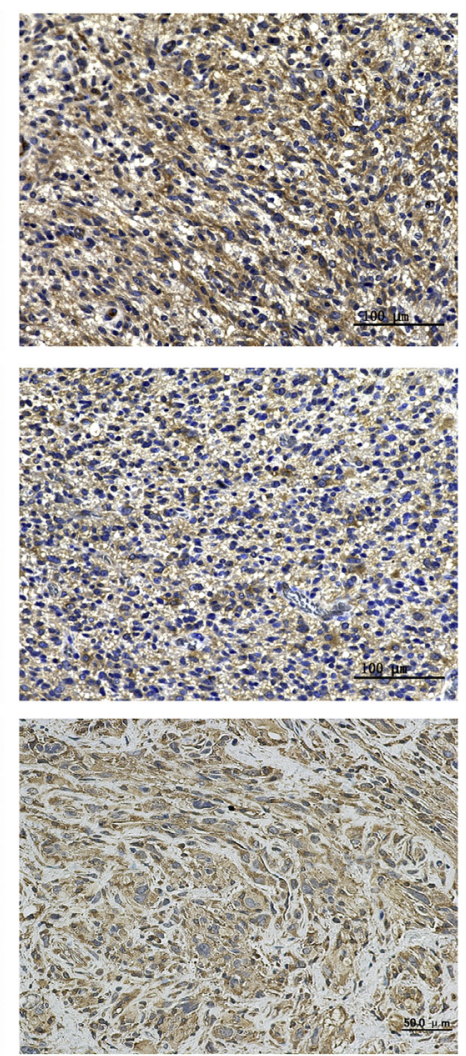

B

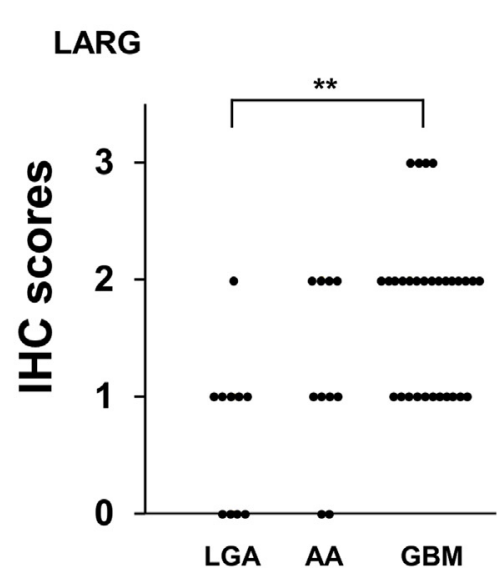

RhoC

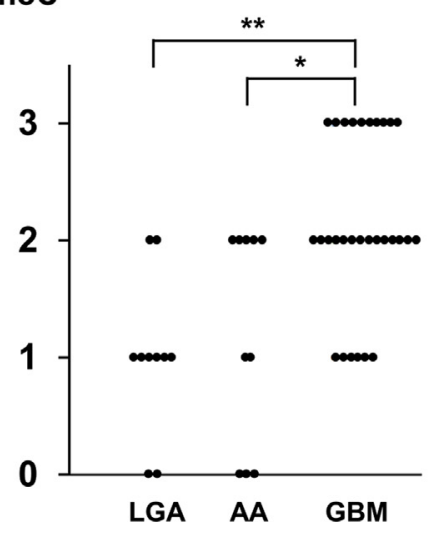

RhoA

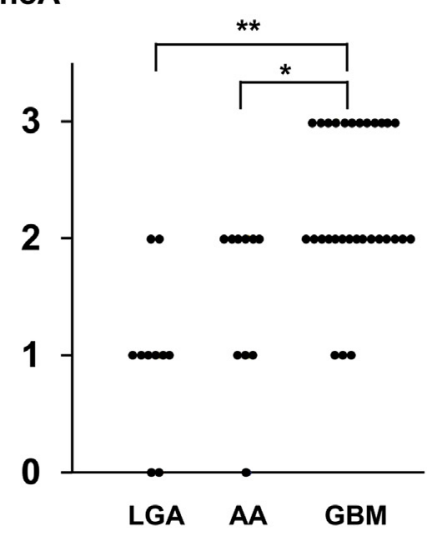

Figure 1 The expression of leukemia-associated Rho guanine nucleotide exchange factor (LARG), ras homolog family member A (RhoA), and ras homolog family member $\mathrm{C}(\mathrm{RhoC})$ increases with glial tumor grades. A: Immunohistochemistry (IHC) analysis of LARG, RhoC, and RhoA expression in low-grade astrocytoma (LGA), anaplastic astrocytoma (AA), and glioblastoma (GBM). B: Dot plot shows the distribution of total IHC scores for LARG, RhoC, and RhoA in all patient specimens. $n=10 \mathrm{LGA}$ and $\mathrm{AA}(\mathbf{A}) ; n=30 \mathrm{GBM}(\mathbf{A}) .{ }^{*} P<0.05,{ }^{* *} P<0.01$. Scale bars: $100 \mu \mathrm{m}$ (A, top and middle rows); $500 \mu \mathrm{m}(\mathbf{A}$, bottom row).

the staining by individuals blinded to the sample identity, as follows: 0 , negative; 1 , weak; 2 , moderate; and 3, strong.

\section{siRNAs and Transfection}

The siRNA duplexes were purchased from Dharmacon (Lafayette, CO). Specific target sequences used were as follows: 5'-AGCACAUAGUGAUGAGAAUCCAUCA-3' (LARG-1; forward), 5'-GGAAUCCUCAACAUACUAAAUAGCA-3' (LARG-2; forward), 5'-AUGGAAAGCAGGUAGAGUU-3' (RhoA-1; forward), 5'-CCCAGAUACCGAUGUUAUACUGAUG-3' (RhoA-2; forward), 5' GAACUAUAUUGCGGACAUU- $3^{\prime}$ (RhoC-1; forward), and 5'-GGACAUGGCGAACCGGAUC-3' (RhoC-2; forward). The control siRNA targeting firefly luciferase (number 

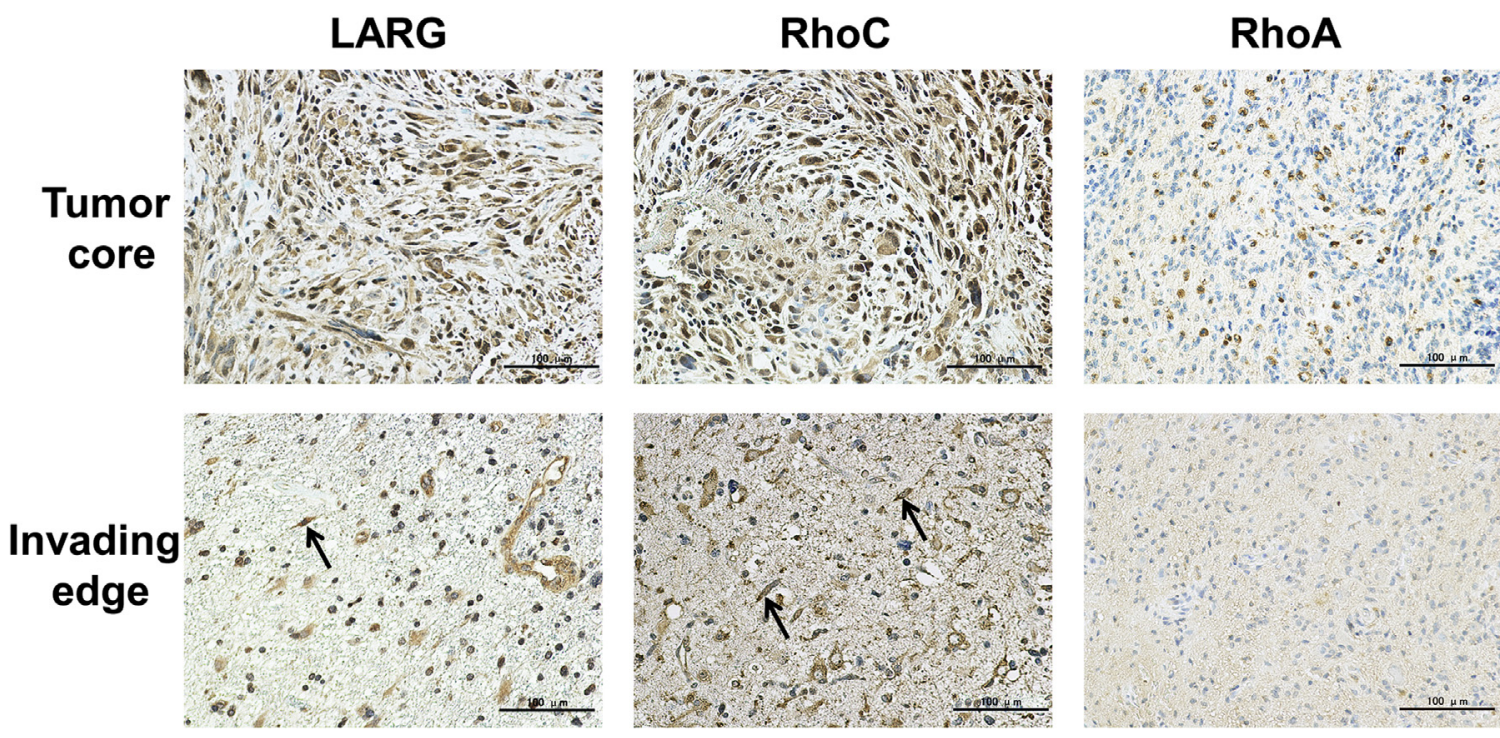

Figure 2 Immunohistochemistry analysis of the expression of leukemia-associated rho guanine nucleotide exchange factor (LARG), ras homolog family member C (RhoC), and ras homolog family member A (RhoA) in the tumor core and invading edge in glioblastoma (GBM). LARG, RhoC, and RhoA are expressed in the tumor core. LARG and RhoC are positively stained in invading cells, but not RhoA. Arrows indicate invasive GBM cells at the tumor edge. Scale bars $=100 \mu \mathrm{m}$.

D-001100-01) was from Dharmacon. The negative control, nontargeting siRNA (number AM4611), was purchased from Ambion (Austin, TX). Cells were plated and allowed to attach for 16 hours and then transfected with indicated siRNAs using Lipofectamine 2000 (Invitrogen), according to the manufacturer's instructions. At 2 or 3 days after transfections, the knockdown of LARG, RhoC, or RhoA was confirmed by immunoblotting.

\section{Immunoblotting}

Immunoblotting of cell lysates and protein concentration was done as described. ${ }^{34}$ Briefly, cells were harvested and lysed in radioimmunoprecipitation assay buffer $(50 \mathrm{mmol} /$ $\mathrm{L}$ Tris $\mathrm{HCl}, \mathrm{pH} 8.0,135 \mathrm{mmol} / \mathrm{L} \mathrm{NaCl}, 1 \% \mathrm{NP}-40,0.1 \%$ SDS, $5 \%$ glycerol, and $0.5 \%$ sodium deoxycholate) supplemented with a cocktail of phosphatase and protease inhibitors (Pierce, Thermo Fisher Scientific, Rockford, IL). The lysates were clarified by centrifugation, and the protein concentration of the lysates was assessed by bicinchoninic acid protein assay (Pierce). Protein lysates were resolved by SDS-PAGE (Bio-Rad, Hercules, CA) and transferred to nitrocellulose membranes (Bio-Rad). Membranes were blocked in 5\% bovine serum albumin in Tris-buffered saline with $0.05 \%$ Tween and sequentially incubated with the appropriate primary antibodies. Protein detection was performed using IRDye-conjugated secondary antibodies with the Odyssey CLx Infrared Imaging System (LI-COR, Lincoln, NE). Densitometric analysis was conducted using Image Studio version 5.2 (LI-COR), and all expression values were normalized to tubulin values.

\section{Glutathione S-Transferase (GST)-Rhotekin Pull-Down Assay}

Activation of RhoA and RhoC was measured using the Rho Activation Assay Kit (Cytoskeleton, Denver, CO), as previously described. ${ }^{34}$ Briefly, cells transfected with control or HA-epitope tagged LARG plasmid were serum starved for 16 hours and lysed. Equal amounts of proteins were assessed for Rho activation.

\section{Cell Migration Assay}

Cells were harvested, resuspended in Dulbecco's modified Eagle's medium with $0.1 \%$ bovine serum albumin $\left(1 \times 10^{5}\right.$ cells $/ 200 \mu \mathrm{L}$ ), seeded in triplicate into collagen-coated transwell chamber inserts $(8-\mu \mathrm{m}$ pore size; number 353097; FALCON, Corning, NY), and allowed to migrate toward Dulbecco's modified Eagle's medium containing $10 \%$ serum in the bottom chamber. After incubation for 24 hours at $37^{\circ} \mathrm{C}$, cells on the top of the membrane were scraped off using a cotton swab. The migrated cells on the lower surface of the membrane were fixed with $4 \%$ paraformaldehyde (Affymetrix, Santa Clara, CA) and stained with ProLong Gold Antifade reagent with DAPI (number 8961; Cell Signaling Technology). For each experiment, five random high-power fields were counted.

\section{Organotypic Brain Slice Invasion Assay}

An ex vivo invasion assay on rat brain slices was performed, as described previously. ${ }^{38,39}$ Briefly, glioma cells $\left(1 \times 10^{5}\right)$ stably expressing green fluorescent protein were transiently transfected with the appropriate siRNAs. Twenty-four hours 
A

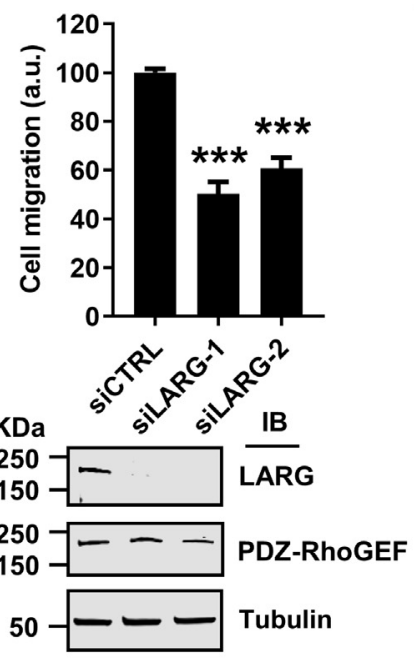

C

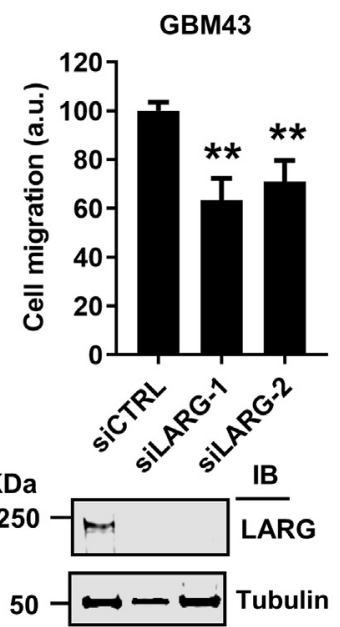

B

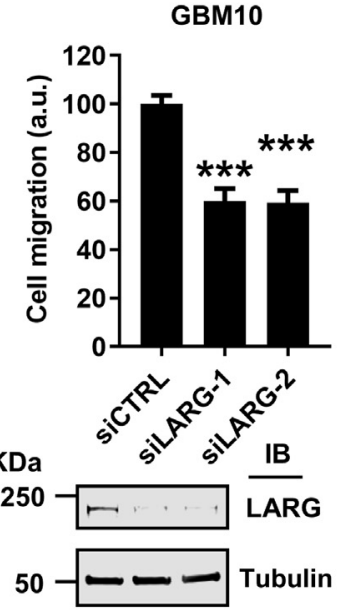

D

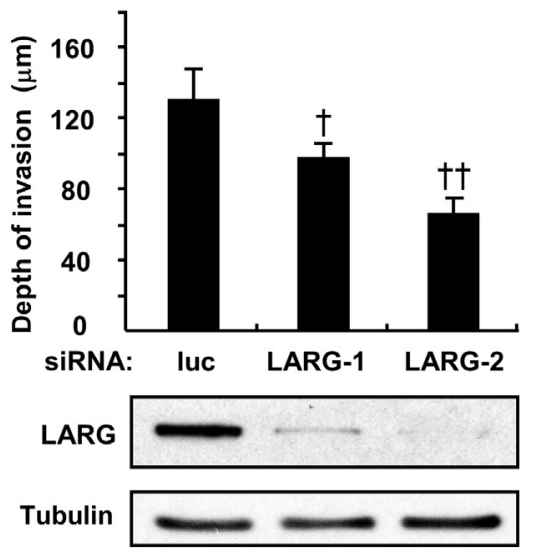

Figure 3 Depletion of leukemia-associated rho guanine nucleotide exchange factor (LARG, also known as ARHGEF12) inhibits glioblastoma cell migration in vitro and invasion ex vivo. A-C: Top panels: U87 (A), glioblastoma (GBM) 10 (B), and GBM43 (C) cells were transfected with the indicated siRNAs and then assayed for migration through 8- $\mu \mathrm{m}$ pore size membranes. Migrated cells were visualized by DAPI staining 24 hours after plating and quantified. Bottom panels: Lysates of cells transfected with indicated siRNAs were blotted with the indicated antibodies. D: U87 cells stably expressing green fluorescent protein were transfected with the indicated siRNAs for 24 hours. Cells were subsequently implanted into the bilateral putamen on rat organotypic brain slices and observed after 48 hours. Depth of invasion was quantified by confocal microscopy. Data represent the depth of invasion. Immunoblot (IB) analysis confirms the efficiency of knockdown of LARG using two independent siRNAs. Data are expressed as means \pm SD (A-C, top panels, and D). $n=4$ to 6 independent experiments (D). ${ }^{*} P<0.05,{ }^{*} P<0.01$, and $* * * P<0.001$ versus siCTRL; ${ }^{\dagger} P<0.05,{ }^{\dagger \dagger} P<0.01$ versus luc. a.u., arbitrary unit; luc, luciferase; PDZ-RhoGEF, rho guanine nucleotide exchange factor 11; siCTRL, control siRNA; siLARG, small interfering RNA targeting LARG. later, cells were gently deposited ( $0.5 \mu \mathrm{L}$ transfer volume) onto the bilateral putamen of the brain slice and incubated under standard conditions. Forty-eight hours after seeding the cells, glioma cell invasion into the rat brain slices was detected and quantified using an LSM 5 Pascal laserscanning confocal microscope (Zeiss, Thornwood, NY), as described previously. ${ }^{40}$ The extent of glioma cell invasion was represented as the depth where the area of fluorescent tumor cells was half of the maximum area at the surface.

\section{Colony Formation Assay}

A colony formation assay was used to assess cell survival, as described previously. ${ }^{41}$ Briefly, GBM10 and GBM43 PDX cells were transfected with indicated siRNAs for 48 hours, followed by treatment with vehicle (dimethyl sulfoxide) or 500 $\mu \mathrm{mol} / \mathrm{L}$ temozolomide (TMZ) for additional 24 hours. Cells were harvested, replated in triplicate in six-well plates $(1500$ cells/well), and cultured for 10 days. Colonies were fixed with a solution of $10 \%$ acetic acid and $10 \%$ methanol and stained with
$0.5 \%$ crystal violet (Sigma, St. Louis, MO). The number of colonies consisting of $\geq 50$ cells was counted manually. Results are normalized to cells transfected with a control siRNA and treated with vehicle and represented as means $\pm \mathrm{SD}$.

\section{Statistical Analysis}

Statistical analyses were performed by the two-sample $t$-test using GraphPad Prism 8.0 (GraphPad, Inc., San Diego, CA). Statistical difference of the H-scores for LARG, RhoC, and RhoA among different tumor grades was performed by the Kruskal-Wallis test using GraphPad Prism 8.0. $P<0.05$ was considered significant.

\section{Results}

\section{LARG Expression Correlates with Glial Tumor Grade}

To examine the protein expression levels of LARG as well as its substrates RhoA and RhoC in gliomas, IHC was 

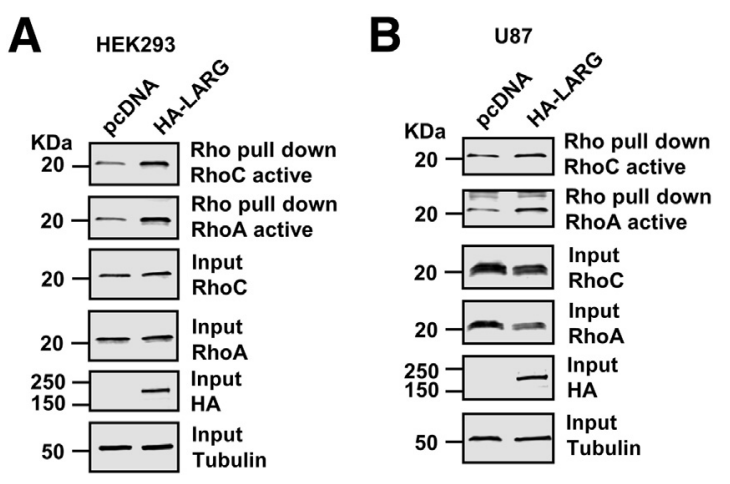

Figure 4 Leukemia-associated rho guanine nucleotide exchange factor (LARG) can promote guanine nucleotide exchange on ras homolog family members A (RhoA) and C (RhoC). HEK293 cells (A) and U87 cells (B) were transfected with human influenza hemagglutinin (HA)-epitope-tagged LARG or empty pcDNA expression vector (pcDNA) for 24 hours and then serum starved overnight. Rho activities in cell lysates were measured using glutathione S-transferase (GST)Rhotekin-rho binding domain (RBD) pull-down assay. pcDNA, empty pcDNA expression vector.

performed on 50 astrocytoma samples of different tumor grades. IHC analysis showed that expression level of LARG, RhoA, and RhoC increases with glial tumor grade and is highest in grade IV astrocytomas (GBM) (Figure 1). Closer inspection indicated a differential staining pattern. LARG and RhoC proteins are strongly expressed in the tumor core (Figure 2). RhoA expression was also observed in the tumor core but to a much lesser extent than either LARG or RhoC. Interestingly, in the invasive edge, expression of LARG and RhoC was readily observed in the invading cells, whereas staining for RhoA was largely absent (Figure 2).

\section{siRNA-Mediated Depletion of LARG Inhibits GBM Cell Migration and Invasion}

To investigate the role of LARG in GBM cell migration, LARG expression was silenced in U87 cells by siRNA and the effect on cell migration was examined using a transwell migration assay. We found that siRNA-mediated knockdown of LARG in U87 cells resulted in a significant inhibition of cell migration relative to U87 cells transfected with a negative control siRNA (Figure 3A). Immunoblotting analysis of transfected cells showed efficient knockdown of LARG expression using two independent siRNAs (Figure 3A). Immunoblotting also indicated specificity of the knockdown as transfection with either siRNA-1 or siRNA-2, targeting LARG, did not change the expression levels of the closely related family member PDZRhoGEF (Figure 3A). LARG expression was also silenced in two primary GBM PDX cell lines, GBM10 and GBM43, and the effect on cell migration was examined. Consistent with the results obtained with U87 cells, siRNA-mediated knockdown of LARG in both GBM10 and GBM43 resulted in a significant inhibition of cell migration relative to the cells transfected with a negative control siRNA (Figure 3, B and C). Immunoblotting analysis of transfected cells showed specific knockdown of LARG expression using two independent siRNAs (Figure 3, B and C). Next, the effect of depleting LARG on cell invasion using an ex vivo rat brain slice model was determined. ${ }^{42}$ U87 cells were transfected with siRNAs targeting LARG or a control siRNA targeting firefly luciferase and seeded onto a brain slice. Forty-eight hours later, cell invasion into the brain slice was quantified using confocal microscopy. siRNA-mediated depletion of LARG in U87 cells resulted in a significant inhibition in the depth of invasion compared with U87 cells transfected with the control siRNA, supporting a role for LARG in glioma cell invasion (Figure 3D). Together, the results support a role for LARG in GBM cell migration and invasion.

\section{RhoC Is Required for GBM Cell Migration and Invasion}

LARG has previously been shown to promote nucleotide exchange of RhoA, but not Rac1 or Cdc42. ${ }^{27}$ Whether LARG can stimulate guanine nucleotide exchange on $\mathrm{RhoC}$, which is highly homologous to RhoA, is not known. HEK293 cells were transfected with HA epitope-tagged LARG or with the vector pcDNA3. The activation of both RhoA and RhoC in these cell lysates was determined utilizing a GST-rho binding domain (RBD) pull-down assay. ${ }^{43}$ Increased expression of LARG resulted in the activation of both RhoC and RhoA in HEK293 cells (Figure 4A). Similar results were obtained using U87 cells transfected with HA epitope-tagged LARG, demonstrating that LARG can stimulate nucleotide exchange on both RhoA and RhoC (Figure 4B).

To examine the role of RhoA and RhoC in GBM cell migration, the expression of $\mathrm{RhoC}$ and RhoA was silenced by siRNAs and the effect of depleting RhoC or RhoA on cell migration was examined using the transwell assay. Knockdown specificity of the siRNAs targeting RhoC or RhoA was confirmed by immunoblotting (Figure 5A). Knockdown of RhoC in U87 cells significantly inhibited cell migration relative to U87 cells transfected with the control siRNA. In contrast, knockdown of RhoA resulted in a significant increase in cell migration relative to the control cells (Figure 5A). The expression of RhoA or RhoC was also silenced in the two primary PDX cell lines, GBM10 and GBM43, and the effect on cell migration was examined. Similar to the results obtained with U87 cells, siRNA-mediated knockdown of RhoC in both GBM10 and GBM43 resulted in a significant inhibition of cell migration relative to the cells transfected with a negative control siRNA, whereas depletion of RhoA in both GBM10 and GBM43 resulted in a significant increase in cell migration compared with the cells transfected with a negative control siRNA (Figure 5, B and C). Immunoblotting analysis of the transfected cells confirmed specific knockdown of RhoA and RhoC expression using two independent siRNAs each (Figure 5, B and C). To substantiate the results of the in vitro cell migration assay, the effects of knockdown of RhoC or RhoA on cell invasion using the ex vivo brain slice model were also examined. U87 cells were transfected with either siRNAs targeting RhoC or RhoA or the control siRNA (luciferase) and seeded onto the brain slice. Forty-eight hours later, cell invasion into the brain slice was quantified using confocal 
A
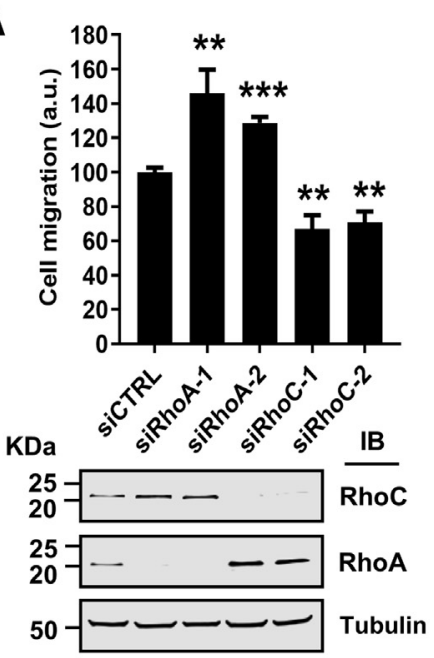

C
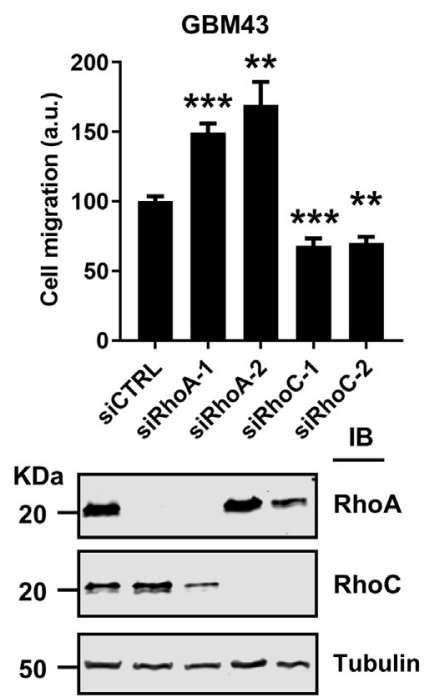

B

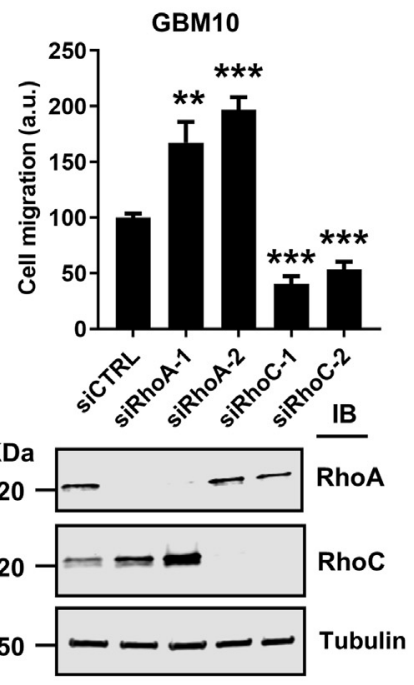

D

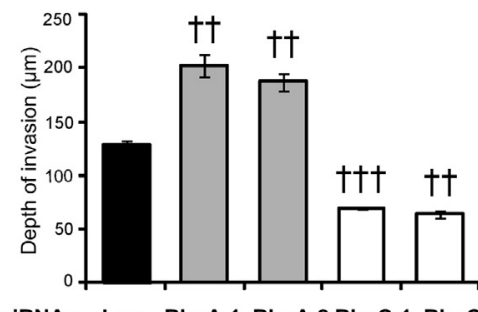

siRNAs: Luc RhoA-1 RhoA-2 RhoC-1 RhoC-2

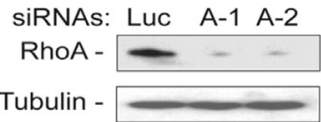

SiRNAs: LuC C-1 C-2

RhoC -

Tubulin -
Figure 5 Ras homolog family members A (RhoA, also known as RHOA) and ( (RhoC, also known as RHOC) have differing roles in cell migration in vitro and cell invasion ex vivo. A-C: Cell migration assay for U87 cells (A), glioblastoma (GBM) 10 cells (B), and GBM43 cells (C) transfected with indicated siRNAs. Twenty-four hours after transfection with siRNAs, cells were serum starved overnight, seeded onto the upper chamber of $8-\mu \mathrm{m}$ pore size transwell inserts, and allowed to migrate for 24 hours. Migrated cells were visualized by DAPI staining and quantified. Immunoblotting confirms the knockdown of RhoA and RhoC. D: U87 cells stably expressing green fluorescent protein were transfected with the indicated siRNAs. At 24 hours after transfection, cells were seeded onto the bilateral putamen of rat brain slices. Depth of invasion was quantified 48 hours after seeding by confocal microscopy. Data represent the depth of invasion. Immunoblot (IB) analysis confirms the efficiency of knockdown of RhoA and RhoC using two independent siRNAs. Data are expressed as means \pm SD (D). $n=4$ to 6 independent experiments (D). ${ }^{* *} P<0.01,{ }^{* * *} P<0.001$ versus siCTRL; ${ }^{\dagger} P<0.01,{ }^{\dagger \dagger \dagger} P<0.001$ versus luc. a.u., arbitrary unit; Luc, luciferase; siCTRL, control siRNA; siRho, small interfering RNA targeting rho. microscopy. Knockdown of RhoC or RhoA was confirmed by immunoblotting (Figure 5D). Results of the brain slice assay were consistent with the results of the in vitro migration assay. Knockdown of RhoC in U87 cells resulted in a significant inhibition in the depth of invasion relative to U87 cells transfected with the control siRNA, further supporting a role for RhoC in glioma cell invasion (Figure 5D). In contrast, knockdown of RhoA in U87 cells increased the depth of invasion relative to U87 cells transfected with control siRNA, suggesting differential roles for RhoC and RhoA in GBM cell invasion. Taken together, the results suggest that RhoC plays a role in GBM cell migration and invasion.

\section{Depletion of RhoA Results in the Decreased Phosphorylation of Myosin II}

Previous studies have shown that myosin II is required for GBM cell migration and invasion. ${ }^{44}$ The activity of myosin II is controlled by the phosphorylation of the regulatory light chain, which is largely catalyzed by two regulatory kinases: Rho-kinase and myosin light chain kinase. ${ }^{45,46}$ It has also been reported that RhoA stimulates phosphorylation of MLC via rho-associated protein kinase in amoeboid-driven migration. ${ }^{47}$ Given that LARG can modulate the activity of RhoA and RhoC (Figure 4), it was examined whether myosin II is downstream of LARG signaling. To determine whether LARG has an effect on the phosphorylation of MLC2, LARG expression was silenced in U87 cells by siRNA and the effect on MLC2 phosphorylation was examined by immunoblotting. Immunoblotting analysis showed that depletion of LARG had no effect on the phosphorylation of MLC2 (Figure 6A). To determine whether knockdown of RhoC or RhoA has an effect on phosphorylation of MLC2, RhoA or RhoC expression was silenced in U87 cells by siRNA and the phosphorylation of MLC2 was examined by immunoblotting. Immunoblotting analysis showed that siRNA-mediated depletion of RhoA, but not RhoC, significantly reduced phosphorylation of MLC2 (Figure 6B). The expression of 


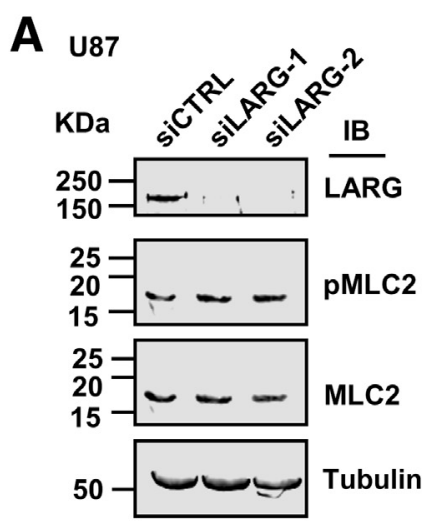

C

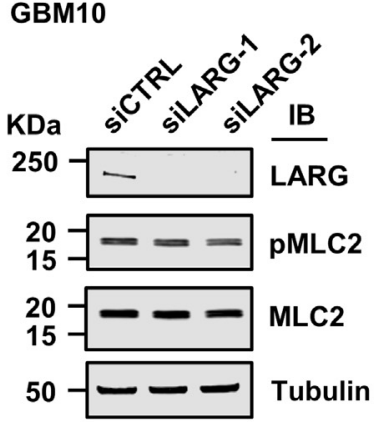

$\mathbf{E}$

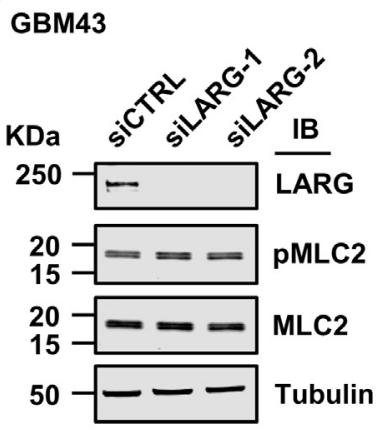

B

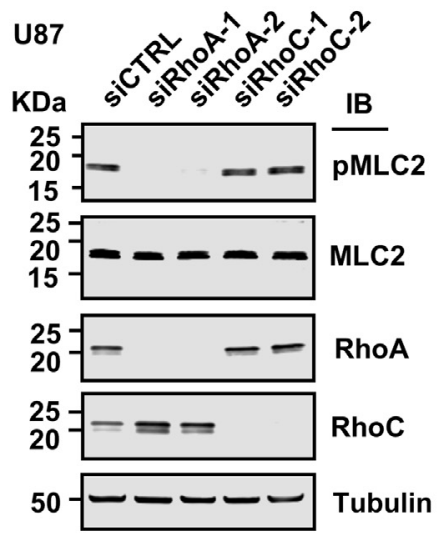

D

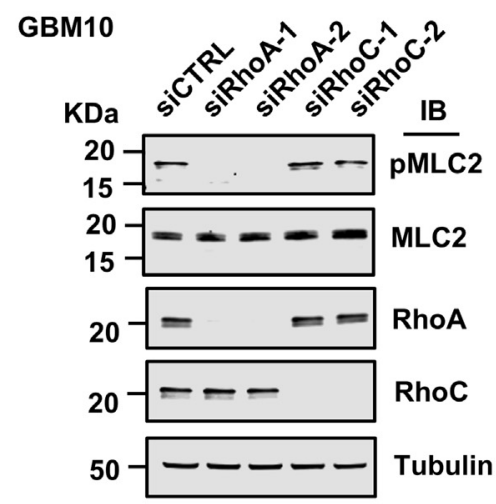

$\mathbf{F}$

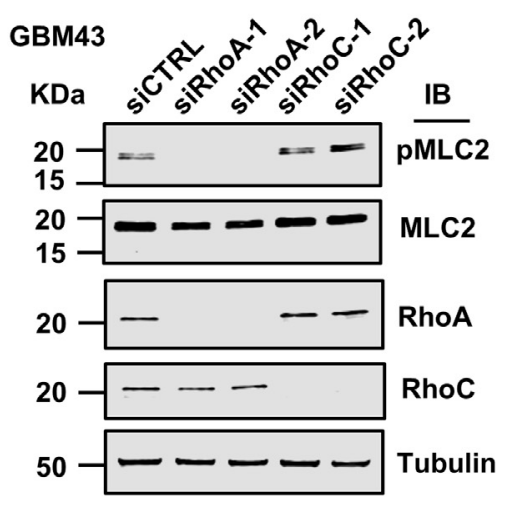

Figure 6 Depletion of ras homolog family member A (RhoA, also known as RHOA) results in the decreased phosphorylation of myosin II. U87 cells (A), glioblastoma (GBM) 10 cells (C), and GBM43 cells (E) were transfected with either nonsilencing siRNA or siRNAs targeting leukemia-associated rho guanine nucleotide exchange factor (LARG, also known as ARHGEF12). Forty-eight hours after transfection, cells were serum starved overnight and directly lysed in sample buffer. The lysates were immunoblotted with the indicated antibodies. U87 cells (B), GBM10 cells (D), and GBM43 cells (F) were transfected with either nonsilencing siRNA or siRNAs targeting RhoA or ras homolog family member $\mathrm{C}$ (RhoC, also known as RHOC). Forty-eight hours after transfection, cells were serum starved overnight and directly lysed in sample buffer. The lysates were immunoblotted with the indicated antibodies. IB, immunoblot; MLC, myosin light chain; PMLC, phosphorylation of MLC; siCTRL, control siRNA; siLARG, small interfering RNA targeting LARG.
LARG, RhoA, or RhoC was also silenced in the two primary PDX cell lines, GBM10 and GBM43, and the effect on phosphorylation of MLC2 was examined. Similar to the results obtained with U87 cells, siRNA-mediated knockdown of LARG or RhoC in both GBM10 and GBM43 had no effect on phosphorylation of MLC2 relative to the cells transfected with a negative control siRNA. In contrast, depletion of RhoA in both GBM10 and GBM43 resulted in a significant reduction in phosphorylation of MLC2 compared with the cells transfected with a negative control siRNA (Figure 6, C-F). These results show LARG and RhoC are dispensable for MLC2 phosphorylation, indicating that other effectors are involved in LARG-RhoC-mediated GBM cell migration and invasion.
Depletion of LARG Sensitizes Glioblastoma Cells to TMZ Treatment

To examine the effect of knockdown of LARG on resistance to glioblastoma cells to TMZ, GBM10 and GBM43 cells were transfected with a negative control siRNA or siRNAs targeting LARG for 48 hours, followed by vehicle (dimethyl sulfoxide) or TMZ treatment for 24 hours. Cells were then harvested, and the effect of LARG silencing and treatments was determined by colony formation assay. The results showed that knockdown of LARG did not affect survival of GBM10 or GBM43 cells, as indicated by similar surviving fractions relative to the cells transfected with a negative control siRNA (Figure 7). Treatment of TMZ alone resulted 

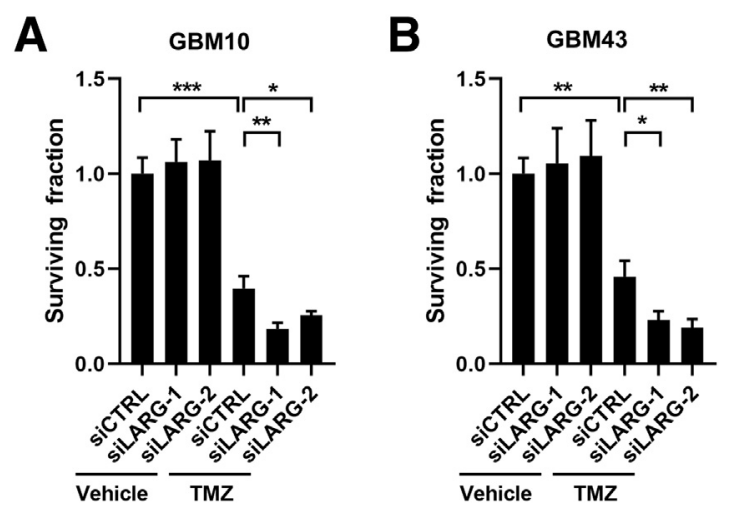

Figure 7 Depletion of leukemia-associated rho guanine nucleotide exchange factor (LARG, also known as ARHGEF12) sensitizes glioblastoma (GBM) 10 and GBM43 cells to temozolomide (TMZ) treatment. GBM10 cells (A) and GBM43 cells (B) were transfected with either nonsilencing siRNA or siRNAs targeting LARG. Forty-eight hours after transfection, cells were treated with vehicle or $500 \mu \mathrm{mol} / \mathrm{L} \mathrm{TMZ}$. After 24 hours, cells were harvested, 1500 cells were replated in triplicate, and the surviving fraction was assessed by colony formation 10 days later. ${ }^{*} P<0.05,{ }^{*} P<0.01$, and $* * * P<0.001$ siCTRL, control siRNA.

in a significant reduction in cell survival relative to vehicle treatment. In addition, TMZ treatment of cells with knockdown of LARG by siRNAs significantly reduced cell survival relative to TMZ treatment of cells with a control siRNA (Figure 7). These data suggest that depletion of LARG can enhance the chemotherapeutic efficacy of TMZ in GBM cells.

\section{Discussion}

These results establish a role for LARG and RhoC in GBM cell invasion. The major findings of this study are as follows: i) IHC analysis demonstrated that the expression level

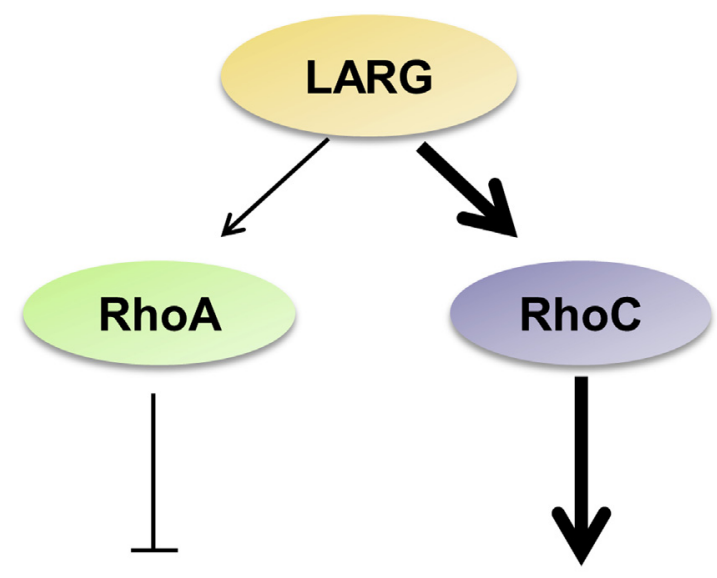

\section{Cell migration/invasion}

Figure 8 Leukemia-associated rho guanine nucleotide exchange factor (LARG) regulates ras homolog family member $C$ (RhoC) to enhance glioblastoma cell migration and invasion. RhoA, ras homolog family member $\mathrm{A}$. of LARG, RhoC, and RhoA increases with glial tumor grade and is highest in GBM. LARG and RhoC expression is enriched in the invading cells. ii) Knockdown of LARG by siRNAs inhibits cell migration in vitro and invasion ex vivo into brain slices. iii) LARG could promote guanine nucleotide exchange on RhoA and RhoC. iv) Depletion of RhoC inhibits GBM cell migration in vitro and invasion ex vivo, whereas depletion of RhoA promotes GBM cell migration and invasion. v) Knockdown of RhoA results in the decreased phosphorylation of myosin II. vi) Depletion of LARG sensitizes GBM cells to TMZ treatment. Taken together, these results demonstrate that LARG plays a role in GBM cell invasion and may provide new insights into potential targets for therapeutic strategies aimed at limiting glioma invasion (Figure 8).

Increased expression of LARG and RhoC in GBM tissues and their role in GBM cell invasion suggest that LARG and RhoC may represent novel potential targets for therapeutic intervention in GBM. Targeting Rho activation with GEF inhibitors has been considered a potentially promising anticancer therapy. For example, compound A13, an inhibitor for the RhoGEF Lbc, has been shown to inhibit Rho signaling as well as cell migration and invasion in prostate cancer cells. ${ }^{48}$ Of note, the expression of LARG and RhoC is enriched in the invasive edge, which is consistent with their functions in cell invasion. Depletion of LARG by siRNAs inhibits cell migration and invasion in GBM, consistent with the observation that depletion of LARG inhibits p90 ribosomal S6 kinase 2-driven GBM cell migration and invasion. ${ }^{49}$ Despite the fact that LARG was originally discovered as an oncogene in acute myeloid leukemia, ${ }^{25}$ LARG has also been identified as a candidate tumor suppressor gene in human breast and colorectal cancer. ${ }^{50}$ In addition to LARG, two other members of RGSGEF family, including PDZ-RhoGEF and p115RhoGEF, have also been implicated in cancer cell migration and invasion. ${ }^{51,52}$ A previous study has shown that PDZ-RhoGEF expression is increased in GBM, and increased expression of PDZ-RhoGEF stimulates TROY-mediated GBM cell migration. ${ }^{34}$ In contrast, silencing PDZ-RhoGEF inhibits GBM cell invasion, increases sensitivity to TMZ, and extends survival in a preclinical intracranial xenograft model. ${ }^{34}$ Future studies are necessary to determine the role of LARG in resistance to chemotherapy and radiotherapy as well as survival.

The high expression levels of RhoA and RhoC during glioma progression suggest that these small GTPases perform important functions in glioma. This is consistent with a growing body of evidence reporting overexpression of these GTPases in several types of cancer, and in many cases their expression correlated with tumor progression. ${ }^{6}$ Similar to our findings showing RhoA expression positively associated with glial tumor grade, a previous study has shown that RhoA expression is positively correlated with the degree of malignancy of astrocytomas. ${ }^{53}$ In addition, proteomic analysis has identified increased expression 
levels of RhoA in high-grade gliomas, and IHC further verified the observation that RhoA was more abundantly expressed in high-grade tumors than in low-grade tumors. ${ }^{54}$ The studies of RhoA function in glioma remain largely correlative. ${ }^{55}$ It has been reported that RhoA has been involved in golgi phosphoprotein 3 (GOLPH3)-mediated glioma cell migration and invasion. ${ }^{56}$ It has shown that RhoA activation is essential for RHPN2-mediated cell invasion in gliomas. ${ }^{57}$ Similar findings showing RhoA has an inhibitory role in cell invasion have been reported for invasion of breast tumor cells and prostate cancer cells. ${ }^{9,11,58}$ Furthermore, overexpression of a constitutively active RhoA variant (RhoAQ63L) resulted in decreased cell invasiveness of breast cancer cells. ${ }^{58}$ In this study, knockdown of RhoA stimulates GBM cell migration and invasion, supporting a negative regulatory role for RhoA. It is well known that RhoA interacts with its effector rho-associated protein kinase, which, in turn, activates myosin light-chain kinase (MLCK), resulting in activation of myosin. ${ }^{59}$ Herein, knockdown of RhoA resulted in reduced phosphorylation of MLC2 relative to the control siRNA group, possibly because of inhibition of RhoA/rho-associated protein kinase pathway. However, reduced phosphorylation of MCL2, caused by depletion of RhoA, may imply that knockdown of RhoA would inhibit cell migration, which contradicts our observation that knockdown of RhoA stimulates GBM cell migration and invasion. This result was consistent with the observations in prostate cancer cells, where selective knockdown of RhoA, but not RhoC, resulted in decreased phosphorylation of MLC2.$^{60}$ One possible explanation is that Rac1 and RhoA have mutual antagonism in cell invasion, and inhibition of RhoA increased Racl activation, leading to stimulation of cell migration and invasion..$^{55}$ Future studies will focus on the mechanism by which LARG modulates actin reorganization to promote GBM invasion and how the temporal dynamics of RhoA and RhoC expression/activity coordinately regulate cell motility.

Other studies have shown that RhoC expression correlates with increased invasion in several tumor types. ${ }^{12,14,16,19,61}$ Our study is consistent with a primary role performed by RhoC in tumor cell invasion. Although LARG and RhoC are required for GBM cell invasion, RhoA appears to have an inhibitory role. These functions may be performed by RhoC unique effectors, distinct from those that it shares with RhoA. One such protein is formin like 2 (FMNL2), a formin-like factor that drives invasive cell motility specifically downstream of RhoC. ${ }^{62}$ Another example is FMNL3, which is involved in RhoC-driven cancer cell invasion. ${ }^{11}$ The identity of unique downstream effectors of LARG-RhoC modulating GBM cell invasion is still under investigation. It has been proposed that invasion and proliferation in GBM are dichotomous. ${ }^{63}$ It has been observed that invasive glioma cells exhibit increased resistance to cytotoxic agents, whereas treatment with migration inhibitors can sensitize migrating cells to cytotoxic agents. ${ }^{64}$ As knockdown of RhoC significantly inhibits GBM cell migration and invasion, future studies are necessary to determine the role of RhoC in cell proliferation and resistance to chemotherapy and radiotherapy.

In summary, we have identified the LARG-RhoC pathway as an important signaling pathway involved in GBM cell invasion. Overall, we envision that LARG holds potential as an unappreciated therapeutic target to limit GBM cell invasion and decrease therapeutic resistance.

\section{References}

1. Ostrom QT, Cioffi G, Gittleman H, Patil N, Waite K, Kruchko C, Barnholtz-Sloan JS: CBTRUS statistical report: primary brain and other central nervous system tumors diagnosed in the United States in 2012-2016. Neuro Oncol 2019, 21:v1-v100

2. Stupp R, Taillibert S, Kanner A, Read W, Steinberg D, Lhermitte B, Toms S, Idbaih A, Ahluwalia MS, Fink K, Di Meco F, Lieberman F, Zhu JJ, Stragliotto G, Tran D, Brem S, Hottinger A, Kirson ED, Lavy-Shahaf G, Weinberg U, Kim CY, Paek SH, Nicholas G, Bruna J, Hirte H, Weller M, Palti Y, Hegi ME, Ram Z: Effect of tumor-treating fields plus maintenance temozolomide vs maintenance temozolomide alone on survival in patients with glioblastoma: a randomized clinical trial. JAMA 2017, 318:2306-2316

3. Stupp R, Hegi ME, Mason WP, van den Bent MJ, Taphoorn MJ, Janzer RC, Ludwin SK, Allgeier A, Fisher B, Belanger K, Hau P, Brandes AA, Gijtenbeek J, Marosi C, Vecht CJ, Mokhtari K, Wesseling P, Villa S, Eisenhauer E, Gorlia T, Weller M, Lacombe D, Cairncross JG, Mirimanoff RO; European Organisation for Research; Treatment of Cancer Brain Tumour; Radiation Oncology Groups; National Cancer Institute of Canada Clinical Trials Group: Effects of radiotherapy with concomitant and adjuvant temozolomide versus radiotherapy alone on survival in glioblastoma in a randomised phase III study: 5-year analysis of the EORTC-NCIC trial. Lancet Oncol 2009, 10:459-466

4. Wen PY, Kesari S: Malignant gliomas in adults. N Engl J Med 2008, 359:492-507

5. Vega FM, Ridley AJ: Rho GTPases in cancer cell biology. FEBS Lett 2008, 582:2093-2101

6. Karlsson R, Pedersen ED, Wang Z, Brakebusch C: Rho GTPase function in tumorigenesis. Biochim Biophys Acta 2009, 1796:91-98

7. Wheeler AP, Ridley AJ: Why three Rho proteins? RhoA, RhoB, RhoC, and cell motility. Exp Cell Res 2004, 301:43-49

8. Ridley AJ: RhoA, RhoB and RhoC have different roles in cancer cell migration. J Microsc 2013, 251:242-249

9. Simpson KJ, Dugan AS, Mercurio AM: Functional analysis of the contribution of RhoA and RhoC GTPases to invasive breast carcinoma. Cancer Res 2004, 64:8694-8701

10. Bellovin DI, Simpson KJ, Danilov T, Maynard E, Rimm DL, Oettgen P, Mercurio AM: Reciprocal regulation of RhoA and RhoC characterizes the EMT and identifies RhoC as a prognostic marker of colon carcinoma. Oncogene 2006, 25:6959-6967

11. Vega FM, Fruhwirth G, Ng T, Ridley AJ: RhoA and RhoC have distinct roles in migration and invasion by acting through different targets. J Cell Biol 2011, 193:655-665

12. Kleer CG, Griffith KA, Sabel MS, Gallagher G, van Golen KL, Wu ZF, Merajver SD: RhoC-GTPase is a novel tissue biomarker associated with biologically aggressive carcinomas of the breast. Breast Cancer Res Treat 2005, 93:101-110

13. Faried A, Faried LS, Kimura H, Nakajima M, Sohda M, Miyazaki T, Kato H, Usman N, Kuwano H: RhoA and RhoC proteins promote both cell proliferation and cell invasion of human oesophageal squamous cell carcinoma cell lines in vitro and in vivo. Eur J Cancer 2006, 42:1455-1465

14. Kondo T, Sentani K, Oue N, Yoshida K, Nakayama H, Yasui W: Expression of RHOC is associated with metastasis of gastric carcinomas. Pathobiology 2004, 71:19-25 
15. Islam M, Lin G, Brenner JC, Pan Q, Merajver SD, Hou Y, Kumar P, Teknos TN: RhoC expression and head and neck cancer metastasis. Mol Cancer Res 2009, 7:1771-1780

16. Clark EA, Golub TR, Lander ES, Hynes RO: Genomic analysis of metastasis reveals an essential role for RhoC. Nature 2000, 406:532-535

17. Ruth MC, Xu Y, Maxwell IH, Ahn NG, Norris DA, Shellman YG: RhoC promotes human melanoma invasion in a PI3K/Akt-dependent pathway. J Invest Dermatol 2006, 126:862-868

18. Boone B, Van Gele M, Lambert J, Haspeslagh M, Brochez L: The role of RhoC in growth and metastatic capacity of melanoma. J Cutan Pathol 2009, 36:629-636

19. Shikada Y, Yoshino I, Okamoto T, Fukuyama S, Kameyama T, Maehara Y: Higher expression of RhoC is related to invasiveness in non-small cell lung carcinoma. Clin Cancer Res 2003, 9:5282-5286

20. Horiuchi A, Imai T, Wang C, Ohira S, Feng Y, Nikaido T, Konishi I: Up-regulation of small GTPases, RhoA and RhoC, is associated with tumor progression in ovarian carcinoma. Lab Invest 2003, 83:861-870

21. Suwa H, Ohshio G, Imamura T, Watanabe G, Arii S, Imamura M, Narumiya S, Hiai H, Fukumoto M: Overexpression of the rhoC gene correlates with progression of ductal adenocarcinoma of the pancreas. Br J Cancer 1998, 77:147-152

22. Wang W, Yang LY, Huang GW, Lu WQ, Yang ZL, Yang JQ, Liu HL: Genomic analysis reveals RhoC as a potential marker in hepatocellular carcinoma with poor prognosis. Br J Cancer 2004, 90:2349-2355

23. Hakem A, Sanchez-Sweatman O, You-Ten A, Duncan G, Wakeham A, Khokha R, Mak TW: RhoC is dispensable for embryogenesis and tumor initiation but essential for metastasis. Genes Dev 2005, 19: 1974-1979

24. Kleer CG, Teknos TN, Islam M, Marcus B, Lee JS, Pan Q, Merajver SD: RhoC GTPase expression as a potential marker of lymph node metastasis in squamous cell carcinomas of the head and neck. Clin Cancer Res 2006, 12:4485-4490

25. Kourlas PJ, Strout MP, Becknell B, Veronese ML, Croce CM, Theil KS, Krahe R, Ruutu T, Knuutila S, Bloomfield CD, Caligiuri MA: Identification of a gene at 11q23 encoding a guanine nucleotide exchange factor: evidence for its fusion with MLL in acute myeloid leukemia. Proc Natl Acad Sci U S A 2000, 97:2145-2150

26. Aittaleb M, Boguth CA, Tesmer JJ: Structure and function of heterotrimeric G protein-regulated Rho guanine nucleotide exchange factors. Mol Pharmacol 2010, 77:111-125

27. Reuther GW, Lambert QT, Booden MA, Wennerberg K, Becknell B, Marcucci G, Sondek J, Caligiuri MA, Der CJ: Leukemia-associated Rho guanine nucleotide exchange factor, a Dbl family protein found mutated in leukemia, causes transformation by activation of RhoA. J Biol Chem 2001, 276:27145-27151

28. Fukuhara S, Chikumi H, Gutkind JS: Leukemia-associated Rho guanine nucleotide exchange factor (LARG) links heterotrimeric G proteins of the G(12) family to Rho. FEBS Lett 2000, 485:183-188

29. Wang Q, Liu M, Kozasa T, Rothstein JD, Sternweis PC, Neubig RR: Thrombin and lysophosphatidic acid receptors utilize distinct rhoGEFs in prostate cancer cells. J Biol Chem 2004, 279:28831-28834

30. Zheng R, Iwase A, Shen R, Goodman OB Jr, Sugimoto N, Takuwa Y, Lerner DJ, Nanus DM: Neuropeptide-stimulated cell migration in prostate cancer cells is mediated by RhoA kinase signaling and inhibited by neutral endopeptidase. Oncogene 2006, 25:5942-5952

31. Kitzing TM, Sahadevan AS, Brandt DT, Knieling H, Hannemann S, Fackler OT, Grosshans J, Grosse R: Positive feedback between Dia1, LARG, and RhoA regulates cell morphology and invasion. Genes Dev 2007, 21:1478-1483

32. Dubash AD, Wennerberg $\mathrm{K}$, Garcia-Mata R, Menold MM, Arthur WT, Burridge K: A novel role for Lsc/p115 RhoGEF and LARG in regulating RhoA activity downstream of adhesion to fibronectin. J Cell Sci 2007, 120:3989-3998

33. Suzuki H, Aoki K, Chiba K, Sato Y, Shiozawa Y, Shiraishi Y, Shimamura T, Niida A, Motomura K, Ohka F, Yamamoto T, Tanahashi K, Ranjit M, Wakabayashi T, Yoshizato T, Kataoka K, Yoshida K, Nagata Y, Sato-Otsubo A, Tanaka H, Sanada M,
Kondo Y, Nakamura H, Mizoguchi M, Abe T, Muragaki Y, Watanabe R, Ito I, Miyano S, Natsume A, Ogawa S: Mutational landscape and clonal architecture in grade II and III gliomas. Nat Genet 2015, 47:458-468

34. Ding Z, Dhruv H, Kwiatkowska-Piwowarczyk A, Ruggieri R, Kloss J, Symons M, Pirrotte P, Eschbacher JM, Tran NL, Loftus JC: PDZ-RhoGEF is a signaling effector for TROY-induced glioblastoma cell invasion and survival. Neoplasia 2018, 20:1045-1058

35. Sarkaria JN, Yang L, Grogan PT, Kitange GJ, Carlson BL, Schroeder MA, Galanis E, Giannini C, Wu W, Dinca EB, James CD: Identification of molecular characteristics correlated with glioblastoma sensitivity to EGFR kinase inhibition through use of an intracranial xenograft test panel. Mol Cancer Ther 2007, 6:1167-1174

36. Louis DN, Perry A, Reifenberger G, von Deimling A, FigarellaBranger D, Cavenee WK, Ohgaki H, Wiestler OD, Kleihues P, Ellison DW: The 2016 World Health Organization classification of tumors of the central nervous system: a summary. Acta Neuropathol 2016, 131:803-820

37. Chikano Y, Domoto T, Furuta T, Sabit H, Kitano-Tamura A, Pyko IV, Takino T, Sai Y, Hayashi Y, Sato H, Miyamoto K, Nakada M, Minamoto T: Glycogen synthase kinase 3beta sustains invasion of glioblastoma via the focal adhesion kinase, Rac1, and c-Jun N-terminal kinase-mediated pathway. Mol Cancer Ther 2015, 14:564-574

38. Chuang YY, Tran NL, Rusk N, Nakada M, Berens ME, Symons M: Role of synaptojanin 2 in glioma cell migration and invasion. Cancer Res 2004, 64:8271-8275

39. Nakada M, Niska JA, Miyamori H, McDonough WS, Wu J, Sato H, Berens ME: The phosphorylation of EphB2 receptor regulates migration and invasion of human glioma cells. Cancer Res 2004, 64: 3179-3185

40. Matsumura H, Ohnishi T, Kanemura Y, Maruno M, Yoshimine T: Quantitative analysis of glioma cell invasion by confocal laser scanning microscopy in a novel brain slice model. Biochem Biophys Res Commun 2000, 269:513-520

41. Franken NA, Rodermond HM, Stap J, Haveman J, van Bree C: Clonogenic assay of cells in vitro. Nat Protoc 2006, 1:2315-2319

42. Valster A, Tran NL, Nakada M, Berens ME, Chan AY, Symons M: Cell migration and invasion assays. Methods 2005, 37:208-215

43. Ren XD, Kiosses WB, Schwartz MA: Regulation of the small GTPbinding protein Rho by cell adhesion and the cytoskeleton. EMBO J 1999, 18:578-585

44. Beadle C, Assanah MC, Monzo P, Vallee R, Rosenfeld SS, Canoll P: The role of myosin II in glioma invasion of the brain. Mol Biol Cell 2008, 19:3357-3368

45. Amano M, Ito M, Kimura K, Fukata Y, Chihara K, Nakano T, Matsuura Y, Kaibuchi K: Phosphorylation and activation of myosin by Rho-associated kinase (Rho-kinase). J Biol Chem 1996, 271 : 20246-20249

46. Tan JL, Ravid S, Spudich JA: Control of nonmuscle myosins by phosphorylation. Annu Rev Biochem 1992, 61:721-759

47. Ridley AJ: Rho GTPase signalling in cell migration. Curr Opin Cell Biol 2015, 36:103-112

48. Diviani D, Raimondi F, Del Vescovo CD, Dreyer E, Reggi E, Osman H, Ruggieri L, Gonano C, Cavin S, Box CL, Lenoir M, Overduin M, Bellucci L, Seeber M, Fanelli F: Small-molecule protein-protein interaction inhibitor of oncogenic Rho signaling. Cell Chem Biol 2016, 23:1135-1146

49. Shi GX, Yang WS, Jin L, Matter ML, Ramos JW: RSK2 drives cell motility by serine phosphorylation of LARG and activation of Rho GTPases. Proc Natl Acad Sci U S A 2018, 115:E190-E199

50. Ong DC, Ho YM, Rudduck C, Chin K, Kuo WL, Lie DK, Chua CL, Tan PH, Eu KW, Seow-Choen F, Wong CY, Hong GS, Gray JW, Lee AS: LARG at chromosome 11q23 has functional characteristics of a tumor suppressor in human breast and colorectal cancer. Oncogene 2009, 28:4189-4200

51. Ma X, Zhao Y, Daaka Y, Nie Z: Acute activation of beta2-adrenergic receptor regulates focal adhesions through betaArrestin2- and 
p115RhoGEF protein-mediated activation of RhoA. J Biol Chem 2012, 287:18925-18936

52. Patel M, Kawano T, Suzuki N, Hamakubo T, Karginov AV, Kozasa T: Galpha13/PDZ-RhoGEF/RhoA signaling is essential for gastrin-releasing peptide receptor-mediated colon cancer cell migration. Mol Pharmacol 2014, 86:252-262

53. Yan B, Chour HH, Peh BK, Lim C, Salto-Tellez M: RhoA protein expression correlates positively with degree of malignancy in astrocytomas. Neurosci Lett 2006, 407:124-126

54. Iwadate Y, Sakaida T, Hiwasa T, Nagai Y, Ishikura H, Takiguchi M, Yamaura A: Molecular classification and survival prediction in human gliomas based on proteome analysis. Cancer Res 2004, 64: 2496-2501

55. Fortin Ensign SP, Mathews IT, Symons MH, Berens ME, Tran NL: Implications of Rho GTPase signaling in glioma cell invasion and tumor progression. Front Oncol 2013, 3:241

56. Zhou X, Zhan W, Bian W, Hua L, Shi Q, Xie S, Yang D, Li Y, Zhang X, Liu G, Yu R: GOLPH3 regulates the migration and invasion of glioma cells through RhoA. Biochem Biophys Res Commun 2013, 433:338-344

57. Danussi C, Akavia UD, Niola F, Jovic A, Lasorella A, Pe'er D, Iavarone A: RHPN2 drives mesenchymal transformation in malignant glioma by triggering RhoA activation. Cancer Res 2013, 73: $5140-5150$
58. Kalpana G, Figy C, Yeung M, Yeung KC: Reduced RhoA expression enhances breast cancer metastasis with a concomitant increase in CCR5 and CXCR4 chemokines signaling. Sci Rep 2019, 9:16351

59. Rathinam R, Berrier A, Alahari SK: Role of Rho GTPases and their regulators in cancer progression. Front Biosci (Landmark Ed) 2011, $16: 2561-2571$

60. Brown M, Roulson JA, Hart CA, Tawadros T, Clarke NW: Arachidonic acid induction of Rho-mediated transendothelial migration in prostate cancer. Br J Cancer 2014, 110:2099-2108

61. van Golen KL, Davies S, Wu ZF, Wang Y, Bucana CD, Root H, Chandrasekharappa S, Strawderman M, Ethier SP, Merajver SD: A novel putative low-affinity insulin-like growth factor-binding protein, LIBC (lost in inflammatory breast cancer), and RhoC GTPase correlate with the inflammatory breast cancer phenotype. Clin Cancer Res 1999, 5:2511-2519

62. Kitzing TM, Wang Y, Pertz O, Copeland JW, Grosse R: Formin-like 2 drives amoeboid invasive cell motility downstream of RhoC. Oncogene 2010, 29:2441-2448

63. Giese A, Loo MA, Tran N, Haskett D, Coons SW, Berens ME: Dichotomy of astrocytoma migration and proliferation. Int J Cancer 1996, $67: 275-282$

64. Joy AM, Beaudry CE, Tran NL, Ponce FA, Holz DR, Demuth T, Berens ME: Migrating glioma cells activate the PI3-K pathway and display decreased susceptibility to apoptosis. J Cell Sci 2003, 116:4409-4417 